\section{REVISTA BRASILEIRA DE QUALIDADE DE VIDA}

\title{
Construção da versão abreviada do QWLQ-78: um instrumento de avaliação da qualidade de vida no trabalho
}

\section{Construction of short version of QWLQ-78: a measurement instrument of quality of work life}

\author{
Marceli Cheremeta \\ Universidade Tecnológica Federal do Paraná - UTFPR - Ponta Grossa - Brasil \\ marceli_ch@hotmail.com \\ Bruno Pedroso \\ Universidade Estadual de Campinas - UNICAMP - Campinas - Brasil \\ brunops3@brturbo.com.br \\ Luiz Alberto Pilatti \\ Universidade Tecnológica Federal do Paraná - UTFPR - Ponta Grossa - Brasil \\ lapilatti@utfpr.edu.br \\ João Luiz Kovaleski \\ Universidade Tecnológica Federal do Paraná - UTFPR - Ponta Grossa - Brasil \\ kovaleski@utfpr.edu.br
}

\begin{abstract}
Resumo
O objetivo do presente trabalho é construir a versão abreviada do instrumento de avaliação da qualidade de vida no trabalho (QVT) QWLQ-78. Para tal, utilizou-se da mesma metodologia utilizada pelo Grupo WHOQOL para a construção do instrumento WHOQOL-bref. O presente estudo resultou na criação do QWLQ-bref, em que foram remanescidas 20 questões do instrumento original. Em todos os domínios, tal qual no escore global da QVT, o comparativo entre os resultados do QWLQ-78 e o QWLQ-bref não destoou em mais do que cinco pontos percentuais. Conclui-se que fora possível a disponibilização da versão abreviada do QWLQ-78, que demanda menos tempo para a aplicação e tabulação dos dados, apresentando propriedades psicométricas satisfatórias e resultados fidedignos ao instrumento original.
\end{abstract}

Palavras-chave: qualidade de vida no trabalho, QWQL-78, QWQL-bref.

\begin{abstract}
The objective of this paper is to build the short version of the quality of work life (QWL) measurement instrument QWLQ-78. For that, it was used the same methodology used by the WHOQOL Group for the WHOQOL-bref construction. This study resulted in QWLQ-bref's creation, in which it was remained 20 questions of the original instrument. In all domains, such as in the QWL global score, the comparative of results between QWLQ-78 and QWLQ-bref not differ in more than five percentile points. It concludes that it was possible to create the short version of QWLQ-78, who demands less time to application and tabulation of data, presenting satisfactory psychometrics properties and reliable results such as the original instrument.
\end{abstract}

Keywords: quality of work life, QWQL-78, QWQL-bref. 


\section{Introdução}

O estudo da qualidade de vida (QV) tem feito, cada vez mais, parte de contextos diferenciados, que não buscam apenas a avaliação da QV propriamente dita, mas buscam as relações que podem existir entre tal variável e outras facetas da vida. Dentro deste contexto surgiram ramificações da variável progenitora, tal qual a qualidade de vida relacionada à saúde (QVRS) e a qualidade de vida no trabalho (QVT).

Em virtude da crescente valorização da mensuração da QV e suas variantes, diversos instrumentos de avaliação de tais variáveis foram criados e disponibilizados na comunidade científica. Todavia, o elevado número de itens de instrumento de avaliação pode constituir um fator negativo incipiente deste, ao passo que o consumo extenso de tempo para respondê-lo tende a perfazer com que o instrumento não seja preenchido até o final ou, após um determinado item, as respostas sejam relapsas. Em ambos os caso, ocorre a desfiguração dos resultados da avaliação da variável que está sendo examinada. Nessa perspectiva, o objetivo do presente trabalho é construir uma versão abreviada do QWLQ-78 - para avaliação da QVT -, seguindo a metodologia utilizada pela Organização Mundial da Saúde (OMS) para a criação da versão abreviada do instrumento WHOQOL-100, o WHOQOL-bref.

\section{Qualidade de vida e qualidade de vida no trabalho}

Após a Revolução Industrial, as condições de vida e trabalho tomaram níveis subumanos. As moradias não possuíam mínimas condições de higiene e limpeza, a alimentação não era satisfatória e o trabalho era subumano. Os indivíduos vivenciavam situações que os deixavam cada vez mais vulneráveis às doenças e à fadiga, originadas, respectivamente, pela falta de higiene e pela realização de esforço demasiado durante longos períodos de trabalho (PILATTI, 2005).

A precariedade da qualidade do trabalho torna-o desgastante, sendo que, o trabalhador não apresenta qualidades suficientes para exercer suas atividades de forma satisfatória. Esse cenário desencadeia um prejuízo que transcende a vontade do trabalhador, estendendo-se, também, aos gestores das organizações.

$\mathrm{Na}$ tentativa de obter condições melhores de vida e trabalho, os indivíduos passam a lutar em busca de tais ideais. De acordo com Pilatti (2005, p. 44), as lutas dos trabalhadores surtiram maiores melhoras na QV e trabalho, do que os próprios avanços tecnológicos. E livre do esforço braçal, o trabalhador foi "mecanizado e coisificado".

Através de mudanças e inovações o trabalho foi sendo modelado e transformado, tornandose mais humanizado. As novas faces do trabalho nasceram após a Segunda Guerra Mundial. O mercado que surgiu trouxe consigo diversos avanços científicos e tecnológicos, incluindo diferentes e complexos métodos e ferramentas de trabalho, que fazem parte dessa sociedade, onde existem tanto oportunidades quanto ameaças. Houve uma maior valorização das pessoas, que passaram a ser tratadas como capital humano (PILATTI, 2005).

O mercado de trabalho tornou-se muito mais humanizado. Agora os trabalhadores passam a ter prazer em realizar suas tarefas, de forma que as condições passaram de um nível desumano para um nível aonde se pode conciliar o trabalho e a vida pessoal. Frente a esse cenário é que se iniciou a percepção do nível de correlação entre a qualidade do trabalho e a QV propriamente dita.

Quando surge a inovação do trabalho, um novo ciclo se inicia. Pilatti (2005) afirma que a inovação dentro desses ciclos está estritamente ligada ao mercado, apresentando-se como um modo de sobrevivência de empresas, pois é exatamente o que elas necessitam: um aumento da produtividade. Torna-se perceptível que a inovação é uma ferramenta muito importante, que traz consigo não apenas a mudança física, mas combina esta com a mudança do pensamento dos indivíduos. 
Considerando a valorização do capital humano, percebe-se que este tem se tornado incongruente com seu propósito inicial, pois é preciso produzir mais em curtos períodos de tempo, reduzindo os custos e atendendo padrões de qualidade muito elevados. Assim, a qualificação requerida no mercado de trabalho impõe maiores exigências. Dessa forma, a QV do trabalhador é afetada no interior e exterior do trabalho. Mesmo com as melhorias oriundas das novas tecnologias, essas novas exigências tornam-se uma condição para garantir a empregabilidade do trabalhador (PILATTI, 2005).

As exigências do cenário descrito fazem surtir efeitos negativos. O número de trabalhadores desqualificados aumentou, ao passo que nem todos possuem a qualificação requerida pelo mercado incipiente. Além disso, a qualificação pode não garantir o talento requisitado. Para Pilatti (2005, p. 48), os critérios exigidos pelo setor produtivo, novamente, indicam níveis inumanos.

As condições impostas ao indivíduo para que este tenha um bom cargo, ocasionalmente são tantas e tão específicas, que chegam a dificultar a escolha de um "profissional ideal" em uma sociedade que se desenvolve sem a universalidade de oportunidades. Sendo necessário, não só a inovação por parte daqueles que procuram ter avanços em suas vidas, mas também a conscientização por parte das empresas que têm buscado por profissionais quase inexistentes.

No ambiente empresarial contemporâneo, tem-se a ciência de que as pessoas formam a parte mais ativa nas empresas. Assim, supõe-se que devam ser valorizadas por tal importância. Entretanto, não é esse o cenário que tem sido observado. Com a competição entre os mercados mais globalizados e mais complexos, a idéia da QV do trabalhador foge de sua real finalidade. Em uma sociedade marcada por avanços científicos e tecnológicos e por complexos métodos e instrumentos de trabalho, a troca do trabalho mecânico pelo não-trabalho, não proporcionou avanços significativos na QV dos indivíduos (PILATTI; BEJARANO, 2005).

Em se tratando da QVT, segundo Pillati e Bejarano (2005, p. 89), ela pode ser vista "como um indicador da qualidade da experiência humana no ambiente de trabalho". Tratando-se de um conceito estritamente ligado à satisfação dos trabalhadores quanto à sua produtividade num ambiente seguro, com oportunidades de aprendizagem e treinamento e com equipamentos que facilitem o desempenho de suas funções.

Com isto, percebe-se que a QVT indica não só a qualidade física do indivíduo, mas também sua qualidade mental dentro de um lugar onde existem desafios relacionados com objetos, tecnologias e até mesmo com outras pessoas. Segundo Pilatti e Bejarano (2005, p. 89):

As iniciativas de QVT têm dois objetivos: de um lado, aumentar a produtividade e o desempenho; de outro, melhorar a qualidade de vida no trabalho e a satisfação com o trabalho. Muitos supõem que os dois objetivos estão ligados: uma maneira direta de melhorar a produtividade seria a melhora das condições de e a satisfação com o trabalho, porém, a satisfação e a produtividade do trabalhador não seguem necessariamente trajetos paralelos. Isto não significa que os dois objetivos sejam incompatíveis, nem que sejam totalmente independentes de um outro. Sob determinadas circunstâncias, melhorias nas condições de trabalho contribuirão para com produtividade.

Tal proposição conduz ao entendimento que a QVT pode ter os seus objetivos analisados separadamente, pois esta possui uma tendência natural de melhorar a produtividade, mas melhorando a produtividade, não significa que a QVT também melhorará. Todavia, se os objetivos forem associados, poderão produzir mudanças satisfatórias para a organização e para o trabalhador.

Dentro da sociedade capitalista, as empresas tentam utilizar tudo que podem extrair do processo de produção, a fim de criar um excesso para as corporações. Fazendo isso, estas obtêm consequiências peculiares, tal qual tomar controle sobre os processos de trabalho e produção. E assim, as empresas transformam o trabalho de acordo com as suas necessidades (PILATTI; BEJARANO, 2005).

Para os trabalhadores, as atitudes tomadas pelas empresas não lhes trazem benefícios diretos, ao passo que são atendidas primeiramente as necessidades das corporações, podendo estas não serem as mesmas do trabalhador. Podendo, ainda, até prejudicá-los. 
Frente ao cenário em exame, percebe-se que a QVT depende de diversos fatores, a maioria está relacionada com aspectos da vida no trabalho, mas, além destes, os aspectos da vida de nãotrabalho também estão inseridos. Sendo que a totalidade da QVT depende da harmonia de todos esses aspectos.

Além da relação que a QV possui com a QVT, esta também está inserida num segundo contexto: o da QV relacionada com a saúde. Em se tratando deste, é pertinente ressaltar que avanços substanciais têm sido presenciados pela sociedade. Segundo Fleck (2008), o progresso vindo da medicina tem trazido um significativo prolongamento na expectativa de vida, sendo que algumas doenças consideradas letais passaram a ser curáveis.

A forte relação entre a QV e a saúde fomentou o desenvolvimento de pesquisas na área da medicina. Com a utilização de instrumentos para medição da QV, a medicina pôde melhorar, de forma que, ao se auto-avaliarem, os pacientes passam a conhecer e entender com mais facilidade as características de suas respectivas doenças e tratamento, perfazendo com que haja um aumento da eficácia e rapidez deste.

A introdução do conceito de QV na saúde surgiu na década de 1970, através de seis vertentes: estudos de base epidemiológica sobre a felicidade e o bem estar, que consistiam em pesquisas sobre como as pessoas se sentiam com elas mesmas e com tudo a sua volta; busca de indicadores sociais, como indicadores de desenvolvimento, saúde e educação; insuficiência das medidas objetivas de desfecho em saúde, pois as medidas existentes avaliam mais a doença do que o próprio paciente; psicologia positiva, que trata, juntamente com a doença, de variáveis da vida humana, como coragem, esperança, sabedoria, espiritualidade e criatividade; satisfação do cliente e movimento de humanização da medicina, buscando recolocar a interação do médico com o paciente, como principal fator no sucesso de tratamentos (FLECK, 2008).

A partir destas vertentes da QV, o seu relacionamento com a saúde se expandiu, fazendo da QVRS uma prática mais comum. Antes de criarem um conceito de QRVS através das seis vertentes citadas anteriormente, a utilização da QV para a saúde era pequena, pois não existia um conhecimento geral sobre o assunto. Mas com o passar do tempo tornou-se cada vez mais comum, proferindo um auxílio ímpar a evolução da medicina.

A QV foi, então, seccionada em dois modelos teóricos: o modelo da satisfação e o modelo funcionalista. O modelo da satisfação está estritamente ligado com o aumento das realizações pessoais do indivíduo e a diminuição de suas expectativas. Através disto, este pode alcançar um bom nível de QV, pois quando busca realizações, sente a satisfação através do sucesso. Já no modelo funcionalista, para que se tenha uma boa QV, leva-se em consideração o fato de o indivíduo estar desempenhando seu papel social e suas funções na sociedade de forma satisfatória (FLECK, 2008).

Com a relação criada entre a QV e a saúde, a sociedade foi recompensada. Grandes avanços surgiram e a evolução da medicina foi marcante. Isso perfez com que surgissem reais possibilidades de melhora na QVRS, sendo que os avanços são surtem em todas as áreas. Pois os indivíduos que não têm acesso aos cuidados de saúde, não têm melhoras na QV.

Como os dois contextos, QVT e QVRS, possuem como base a QV propriamente dita, a OMS desenvolveu um instrumento para medição da QV chamado World Health Organization Quality of Life (WHOQOL). Este foi desenvolvido a partir de uma definição da QV posta como "a percepção do indivíduo de sua posição na vida no contexto da cultura e sistema de valores nos quais ele vive e em relação aos seus objetivos, expectativas, padrões e preocupações" (THE WHOQOL GROUP, 1995 apud FLECK, 2000, p. 34).

Ao passo que os resultados retornados por instrumentos de avaliação da QV têm proporcionado avanços na vida dos indivíduos, novos instrumentos foram criados com o objetivo de expandir esta técnica, melhorando cada vez mais os diversos aspectos ligados a QV.

O WHOQOL-100 consiste em um instrumento composto de 100 questões referentes a seis domínios: físico, psicológico, nível de independência, relações sociais, ambiente e espiritualidade/religião/crenças pessoais. Estas 100 questões estão divididas em 24 grupos, denominados "facetas", sendo que cada uma delas possui quatro questões. O conjunto de facetas é 
denominado "domínio", e diferentemente das mesmas, os domínios não constituem um número igual de facetas, podendo variar de uma até oito (PEDROSO et al. 2009).

O WHOQOL-100 foi construído objetivando possibilitar uma avaliação da QV de forma global. Porém, ainda que muito utilizado, este apresenta um número de questões relativamente extenso, o que vem a dificultar a sua aplicação. No intuito de suprimir essa fragilidade, o Grupo WHOQOL desenvolveu o WHOQOL-bref, uma versão abreviada do instrumento original.

O instrumento abreviado é composto por 26 questões, divididas em quatro domínios: físico; psicológico; relações sociais e ambiente. Estes domínios também são subdivididos em 24 facetas, assim como no instrumento original. Porém, ao invés de cada faceta possuir quatro questões, elas possuem apenas uma. Sendo que as outras duas questões que faltam para completar o instrumento são sobre a QV de forma global (FLECK, 2000).

Mesmo com a criação desta abreviação do WHOQOL, a medição da QV continuou tendo a mesma validade e confiabilidade, pois ela foi criada levando em consideração os aspectos mais relevantes do instrumento original, sendo feita de modo análogo ao mesmo. E com isso, esta versão abreviada tem sido muito utilizada quando a aplicação do questionário precisa ser feita em menores tempos.

Mesmo com a criação de instrumentos que medem a QV, um grande problema que ainda é encontrado na literatura acerca da QV é a conceituação de tal variável. A sua subjetividade fomenta o surgimento de diferentes definições. Nessa perspectiva, ao se desenvolver um instrumento de avaliação da QV, é importante que a construção deste tenha início com a conceituação de tal variável, ao passo que deve se identificar precisamente qual variável será avaliada.

\section{O instrumento QWLQ-78}

Muitos instrumentos de avaliação da QVT foram criados, dentre os quais pode-se citar o QWLQ-78 (Quality of Working Life Questionnaire - Questionário de Qualidade de Vida no Trabalho), desenvolvido por Reis Junior (2008).

Seguindo a metodologia proposta pelo WHOQOL, Reis Junior (2008, p. 57), conceitua a QVT como "o conjunto de ações desenvolvidas pelas empresas na implantação de melhorias gerenciais, estruturais e tecnológicas, na busca da satisfação e do bem-estar físico, psicológico, social e profissional dos colaboradores".

O primeiro passo para a construção do QWLQ-78 foi definir os indicadores que exercem grande influência sobre a QVT. De acordo com Reis Junior (2008), a escolha destes indicadores originou-se a partir do marco referencial teórico, composto por alguns modelos clássicos de QVT, como os de Walton (1973), Westley (1979); Hackman e Oldham (1983) e Werther e Davis (1983).

O segundo passo foi a criação de uma lista de questões relacionadas aos indicadores definidos. E para que houvesse uma organização adequada destas questões, quatro domínios foram criados: físico/saúde, psicológico, pessoal e profissional (REIS JUNIOR, 2008). Os domínios também foram criados com base no instrumento WHOQOL-100.

Dois dos quatro domínios, o físico e o psicológico, pertencem também ao WHOQOL-100. O domínio pessoal tem relação com quatro dos domínios do WHOQOL-100: nível de independência; relações sociais; meio ambiente e espiritualidade/religião/crenças pessoais. E o domínio profissional foi feito pelo fato do instrumento ter o objetivo de medir a QV especificamente no trabalho (REIS JUNIOR, 2008).

O número de questões, agrupadas por domínio, foi definido de acordo com a quantidade de indicadores enquadrados a cada conceito. O domínio físico apresenta 17 questões, o psicológico apresenta 10, o pessoal apresenta 16 e o profissional apresenta 35. A diferença acentuada do número de questões do domínio profissional, em relação aos outros, deve-se ao fato de que um grande número de indicadores foi enquadrado no conceito desse domínio (REIS JUNIOR, 2008).

Como o instrumento foi desenvolvido para avaliar a QVT, foi considerado que o número de questões relacionadas a este aspecto deveria ser mais expressivo do que o número de questões dos 
outros domínios. Isso foi feito para que fossem abordados o maior número de aspectos possível relacionados com o labor.

As escalas de respostas utilizadas no QWLQ-78 são as mesmas do WHOQOL-100: escalas de respostas do tipo Likert de cinco alternativas, sendo que estas podem variar de acordo com o quadro 1:

Quadro 1: Escala de respostas:

\begin{tabular}{|c|c|c|c|c|}
\hline \multicolumn{5}{|c|}{ Escala de Freqüência } \\
\hline Nada & Muito pouco & Ocasionalmente & Freqüentemente & Sempre \\
\hline Muito baixa & Baixa & Média & Alta & Muito alta \\
\hline Nunca & Raramente & Às vezes & Frequentemente & Sempre \\
\hline Muito ruim & Ruim & Médio & Bom & Muito bom \\
\hline Muito pouco & Pouco & Média & Muito & Completamente \\
\hline
\end{tabular}

Fonte: Reis Junior (2008)

Após a definição de todas as questões e escalas de respostas, foi construído o instrumento piloto.

A aplicação do teste piloto teve como amostra 39 colaboradores de duas empresas, as quais foram analisadas de forma conjunta. Alguns critérios de inclusão e exclusão foram utilizados para definir os participantes do teste: participaram os que aceitaram fazer parte do teste voluntariamente e os que tivessem, no dia do teste, idade igual ou maior a 18 anos, sendo que os que não aceitaram não participaram da amostra (REIS JUNIOR, 2008).

Após a aplicação do teste piloto, alguns termos foram mudados por haver certa dificuldade de compreensão de alguns colaboradores. Os termos e suas modificações foram os seguintes:

Quadro 2: Mudanças de termos

\begin{tabular}{|l|l|}
\hline \multicolumn{1}{|c|}{ Termo anterior } & \multicolumn{1}{c|}{ Termo novo } \\
\hline Relacionamento interpessoal & Relação com chefe, colegas e/ou subordinados. \\
\hline Cefaléia & Dores de cabeça. \\
\hline Fadiga & Cansaço. \\
\hline LER/DORT & Dores e desconfortos originados no trabalho. \\
\hline Dificuldade geográfica & Mudanças, viagens, deslocamentos. \\
\hline
\end{tabular}

A verificação da consistência interna do QWLQ-78 foi realizada a partir da avaliação do Coeficiente alfa de Cronbach. Este coeficiente é um indicador estatístico da confiabilidade de um instrumento psicométrico (REIS JUNIOR, 2008).

O coeficiente alfa de Cronbach obtido na aplicação do piloto foi de 0,92 , sendo considerado de confiabilidade muita alta. Após a aplicação, a ordem das questões foi modificada, de forma que estas se tornassem aleatórias, cujo domínio em que as questões estão inseridas não possa ser identificado pelos respondentes, evitando que estes possam prever uma aproximação para seu índice de QVT (REIS JUNIOR, 2008).

Para a validação de conteúdo do instrumento em exame, foi realizada a seleção de um especialista com grande conhecimento na área da QVT. A validação foi feita por um pesquisador com titulação de doutor, vinculado a programas de pós-graduação stricto senso, atuante de linhas de pesquisas relacionadas à QV e QVT (REIS JUNIOR, 2008).

Os critérios levados em consideração para a validação de conteúdo do QWLQ-78 foram: ter respostas que esclareçam a QVT dos respondentes; refletir o significado de definição dos indicadores; usar linguagem simples, evitando ambigüidades; possuir questões curtas; possuir questões compatíveis com a escala de avaliação; explorar só um problema por questão; evitar referências explícitas em relação a tempo ou outra comparação; ser aplicado a indivíduos de diversos graus de instrução ser formulado como questões e não como afirmações (REIS JUNIOR, 2008). 
Seguindo os critérios pré-estabelecidos, o juiz concluiu que o instrumento atendeu a todos estes e o julgou capaz de avaliar de forma confiável a QVT dos respondentes, considerando-o um instrumento "muito bom" (REIS JUNIOR, 2008).

Após a validação de conteúdo do QWLQ-78, foi realizada a aplicação final. A amostra da aplicação foi composta por colaboradores de quatro cidades do estado do Paraná: Curitiba, Ponta Grossa, Toledo e Pato Branco. As cidades de Ponta Grossa e Toledo foram analisadas juntamente. Todos os participantes da pesquisa atenderam as condições para participar, tendo idade igual ou maior que 18 anos, pelo menos o ensino fundamental completo e respondendo o questionário voluntariamente. A aplicação final do instrumento apresentou coeficiente alfa de Cronbach igual a 0,86, garantindo, portanto, uma consistência interna satisfatória (REIS JUNIOR, 2008).

Em se tratando das questões que constituem o QWLQ-78, no quadro 3 são apresentadas as referentes ao domínio físico/saúde, que aborda aspectos relacionados à saúde, doenças relacionadas ao trabalho e hábitos dos colaboradores:

Quadro 3: Questões referentes ao domínio físico/saúde

\begin{tabular}{|c|c|c|}
\hline Domínio & $\begin{array}{l}\mathbf{N}^{0} \text { da } \\
\text { questão }\end{array}$ & Questão \\
\hline \multirow{17}{*}{$\begin{array}{l}\text { Físico/ } \\
\text { Saúde }\end{array}$} & 1 & Quanto você cuida da sua alimentação? \\
\hline & 6 & Quanto você se preocupa com sua saúde? \\
\hline & 11 & Quanto você se preocupa com dores ou desconfortos no trabalho? \\
\hline & 16 & Em que medida você tem dificuldades para cuidar da sua saúde? \\
\hline & 21 & Você pratica exercício físico regular? \\
\hline & 26 & Você tem alguma dificuldade para dormir? \\
\hline & 31 & Em que medida você avalia o seu sono? \\
\hline & 36 & Em que medida algum problema com o sono prejudica seu trabalho? \\
\hline & 43 & Você sofre com cefaléias (dores de cabeça)? \\
\hline & 48 & Você sofre com dores estomacais? \\
\hline & 53 & Em que medida você necessita de medicamentos para poder trabalhar? \\
\hline & 57 & Você sofre com doenças hereditárias (colesterol, pressão alta)? \\
\hline & 61 & Ao final da jornada de trabalho, o quanto você se sente cansado? \\
\hline & 65 & $\begin{array}{l}\text { Em que medida suas dores e/ou saúde o impede de realizar o que } \\
\text { precisa? }\end{array}$ \\
\hline & 69 & Suas necessidades fisiológicas básicas são satisfeitas adequadamente? \\
\hline & 73 & $\begin{array}{l}\text { Você pratica ginástica laboral ou outro tipo de atividade física na } \\
\text { empresa? }\end{array}$ \\
\hline & 77 & Em que medida você se sente confortável no ambiente de trabalho? \\
\hline
\end{tabular}

Fonte: Reis Junior (2008)

No quadro 4 são mostradas as questões referentes ao domínio psicológico, que aborda aspectos relacionados à satisfação pessoal, motivação no trabalho e auto-estima dos colaboradores:

Quadro 4: Questões referentes ao domínio psicológico

\begin{tabular}{|l|l|l|}
\hline \multirow{4}{*}{ Domínio } & $\begin{array}{l}\mathbf{N}^{\mathbf{o}} \text { da } \\
\text { questão }\end{array}$ & Questão \\
\hline \multirow{5}{*}{ Psicológico } & $\mathbf{2}$ & Em que medida você avalia sua auto-estima? \\
\cline { 2 - 3 } & $\mathbf{7}$ & Quanto você se sente inibido no trabalho devido à sua aparência? \\
\cline { 2 - 3 } & $\mathbf{1 2}$ & Quanto você consegue se concentrar no seu trabalho? \\
\cline { 2 - 3 } & $\mathbf{1 7}$ & $\begin{array}{l}\text { Em que medida algum sentimento negativo (tristeza, desespero) interfere } \\
\text { no seu trabalho? }\end{array}$ \\
\cline { 2 - 3 } & $\mathbf{2 2}$ & Em que medida você avalia sua motivação para trabalhar? \\
\cline { 2 - 4 } & $\mathbf{3 2}$ & $\begin{array}{l}\text { Como você avalia o espírito de camaradagem dos seus colegas de } \\
\text { trabalho? }\end{array}$ \\
\cline { 2 - 4 } & $\mathbf{3 7}$ & Como você avalia sua liberdade de expressão no seu trabalho? \\
\cline { 2 - 3 } & $\mathbf{4 4}$ & Em que medida você avalia o orgulho pela sua profissão? \\
\cline { 2 - 3 } & $\mathbf{4 9}$ & Emo você avalia a segurança no ambiente de trabalho? \\
\hline
\end{tabular}

Fonte: Reis Junior (2008) 
No quadro 5 são mostradas as questões referentes ao domínio pessoal, que aborda aspectos familiares, crenças pessoais e religiosas e aspectos culturais que influenciem o trabalho dos colaboradores:

Quadro 5: Questões referentes ao domínio pessoal

\begin{tabular}{|c|c|c|}
\hline Domínio & $\begin{array}{l}N^{0} \text { da } \\
\text { questão }\end{array}$ & Questão \\
\hline \multirow{16}{*}{ Pessoal } & 3 & Como você avalia a sua capacidade de auto-avaliação no trabalho? \\
\hline & 8 & Em que medida você avalia a qualidade do seu lazer e da sua família? \\
\hline & 13 & Em que medida você tem uma moradia adequada? \\
\hline & 19 & $\begin{array}{l}\text { Você tem alguma dificuldade geográfica em relação ao seu trabalho? } \\
\text { (deslocamento, viagens, mudanças). }\end{array}$ \\
\hline & 23 & Você sofre algum tipo de preconceito no seu trabalho? \\
\hline & 28 & Como você avalia a sua privacidade pessoal no seu trabalho? \\
\hline & 33 & Você se sente realizado com o trabalho que faz? \\
\hline & 38 & $\begin{array}{l}\text { Como você avalia a qualidade da sua relação com seus superiores } \\
\text { e/ou subordinados? }\end{array}$ \\
\hline & 45 & Em que medida sua família avalia o seu trabalho? \\
\hline & $\mathbf{5 0}$ & Você sofre algum tipo de dificuldade na família por causa do seu trabalho? \\
\hline & 54 & $\begin{array}{l}\text { Você sofre algum tipo de dificuldade no trabalho por causa } \\
\text { da sua cultura familiar? }\end{array}$ \\
\hline & 58 & Em que medida seus valores familiares são respeitados no seu trabalho? \\
\hline & 62 & $\begin{array}{l}\text { Em que medida suas crenças pessoais e/ou religiosas são } \\
\text { respeitadas no seu trabalho? }\end{array}$ \\
\hline & 66 & Em que medida você é respeitado pelos seus colegas e superiores? \\
\hline & 70 & $\begin{array}{l}\text { Em que medida você tem os meios de transporte adequados para } \\
\text { trabalhar? }\end{array}$ \\
\hline & 74 & $\begin{array}{l}\text { O quanto você está satisfeito com a sua capacidade de } \\
\text { ajudar os outros no trabalho? }\end{array}$ \\
\hline
\end{tabular}

Fonte: Reis Junior (2008)

E no quadro 6 são mostradas as questões referentes ao domínio profissional, que aborda aspectos organizacionais que influenciem a QVT dos colaboradores:

Quadro 6: Questões referentes ao domínio profissional

\begin{tabular}{|c|c|c|}
\hline Domínio & $\begin{array}{l}N^{0} \text { da } \\
\text { questão }\end{array}$ & Questão \\
\hline \multirow{16}{*}{ Profissional } & 4 & Com que freqüência você falta ao trabalho por motivo de doença? \\
\hline & 5 & Com que freqüência você fica doente devido ao seu trabalho? \\
\hline & 9 & Como você avalia o seu acesso à assistência médica no trabalho? \\
\hline & 10 & $\begin{array}{l}\text { Como você avalia a qualidade da assistência médica recebida no } \\
\text { trabalho? }\end{array}$ \\
\hline & 14 & Como você avalia a sua autonomia no trabalho? \\
\hline & 15 & Como você avalia a sua carga horária de trabalho diário? \\
\hline & 19 & $\begin{array}{l}\text { Como você avalia a cooperação entre os níveis hierárquicos no } \\
\text { trabalho? }\end{array}$ \\
\hline & 20 & Como você avalia a sua liberdade para criar coisas novas no trabalho? \\
\hline & 24 & Como você avalia a igualdade de tratamento entre os funcionários? \\
\hline & 25 & $\begin{array}{l}\text { Com que frequiência você é obrigado a mudar sua rotina em casa } \\
\text { devido ao trabalho? }\end{array}$ \\
\hline & 29 & $\begin{array}{l}\text { Em que medida você confia na disponibilidade e na habilidade de seus } \\
\text { colegas de trabalho? }\end{array}$ \\
\hline & 30 & Em que medida você possui identidade com a tarefa que realiza? \\
\hline & 34 & Com que frequiência você pensa em mudar radicalmente de emprego? \\
\hline & 35 & Em que medida você possui orgulho da organização na qual trabalha? \\
\hline & 39 & $\begin{array}{l}\text { Em que medida você se sente seguro quanto à prevenção de } \\
\text { acidentes de trabalho? }\end{array}$ \\
\hline & 40 & $\begin{array}{l}\text { Como você avalia o seu conhecimento sobre todos os processos de } \\
\text { trabalho da organização? }\end{array}$ \\
\hline
\end{tabular}




\begin{tabular}{|l|l|l|}
\hline \multirow{4}{*}{$\mathbf{4 1}$} & $\begin{array}{l}\text { Em que medida você possui consciência sobre as metas e objetivos do seu } \\
\text { trabalho? }\end{array}$ \\
\cline { 2 - 3 } & $\mathbf{4 2}$ & $\begin{array}{l}\text { Em que medida você gosta do nível de desafio que lhe é proposto no } \\
\text { trabalho? }\end{array}$ \\
\cline { 2 - 3 } & $\mathbf{4 6}$ & $\begin{array}{l}\text { Em que medida você está satisfeito com o seu nível de participação nas } \\
\text { decisões da empresa? } \\
\text { Como você avalia a partilha de ganhos na produtividade na sua } \\
\text { empresa? }\end{array}$ \\
\hline & $\mathbf{5 1}$ & $\begin{array}{l}\text { A sua organização possibilita a construção de uma carreira e/ou de } \\
\text { avanços salariais? }\end{array}$ \\
\hline $\mathbf{5 2}$ & Como você avalia a sua remuneração pelo trabalho? \\
\hline $\mathbf{5 5}$ & $\begin{array}{l}\text { Com que frequiência você necessita de outras fontes de dinheiro } \\
\text { para se sustentar? }\end{array}$ \\
\hline $\mathbf{5 6}$ & $\begin{array}{l}\text { Com que frequiência seus benefícios e direitos trabalhistas são } \\
\text { respeitados? }\end{array}$ \\
\hline $\mathbf{5 9}$ & $\begin{array}{l}\text { Em que medida seus valores familiares são respeitados no seu } \\
\text { trabalho? }\end{array}$ \\
\hline $\mathbf{6 0}$ & $\begin{array}{l}\text { Você está satisfeito com o feedback (retroalimentação) dado pela } \\
\text { organização sobre o seu trabalho? }\end{array}$ \\
\hline $\mathbf{6 3}$ & Você se sente satisfeito com os treinamentos dados pela organização? \\
\hline $\mathbf{6 4}$ & $\begin{array}{l}\text { Em que medida você está satisfeito com a sua capacidade para } \\
\text { aprender? }\end{array}$ \\
\hline $\mathbf{6 7}$ & Você se sente satisfeito com a variedade das tarefas que realiza? \\
\hline $\mathbf{6 8}$ & Você tem sua vida pessoal preservada no ambiente de trabalho? \\
\hline $\mathbf{7 1}$ & Quanto você se sente estável no seu emprego? \\
\hline $\mathbf{7 2}$ & Como você avalia o espírito de camaradagem no seu trabalho? \\
\hline $\mathbf{7 5}$ & $\begin{array}{l}\text { O quanto você consegue dos colegas o apoio que necessita no } \\
\text { trabalho? }\end{array}$ \\
\hline $\mathbf{7 6}$ & $\begin{array}{l}\text { Em que medida você consegue ter acesso rápido as informações no } \\
\text { trabalho? }\end{array}$ \\
\hline $\mathbf{7 8}$ & O quanto você está satisfeito com a sua qualidade de vida no trabalho? \\
\hline
\end{tabular}

Como a escala de respostas utilizada possui cinco alternativas, ou seja, vai de 1 a 5 , de um modo geral, quanto mais positiva a resposta, mais próximo de 5 tende a ser o resultado. Todavia, Reis Junior (2008) julgou necessárias algumas inversões nestas escalas. Sendo que nas questões de escala invertida ocorre o oposto, ou seja, a resposta mais positiva corresponde ao resultado 1, e para chegar a este resultado é necessário subtrair de 6 a resposta dada pelo colaborador .

As questões que adotaram o processo de inversão foram: $4 ; 5 ; 7 ; 16 ; 17 ; 18 ; 23 ; 25 ; 26 ; 34$; $36 ; 43 ; 48 ; 49 ; 50 ; 53 ; 54 ; 55 ; 57 ; 61 ; 65$ (REIS JUNIOR, 2008).

Uma determinação temporal foi criada para a aplicação do instrumento: os colaboradores são instruídos a terem como base suas duas últimas semanas de trabalho. Essa determinação tem o objetivo de estabelecer um padrão nos índices de QVT resultantes, pois estes serão referentes a um mesmo período de tempo. O tempo de duas semanas estipulado é igual ao tempo estipulado no WHOQOL-100, pela OMS (Organização Mundial da Saúde) (REIS JUNIOR, 2008).

No instrumento proposto, Reis Junior (2008) definiu que, para que se obtenha um resultado fidedigno, devem ser obrigatoriamente respondidas $80 \%$ das questões de cada domínio, para que este se torne válido. Isso, em números absolutos, representa um mínimo de 63 questões a serem respondidas no total. Em cada domínio, o mínino de questões a serem respondidas é:

Quadro 7: Número mínimo de questões preenchidas por domínio

\begin{tabular}{|l|c|c|c|}
\hline & $\begin{array}{c}\text { Total de questões } \\
\text { do domínio }\end{array}$ & $\begin{array}{c}\text { Mínimo de questões a } \\
\text { serem preenchidas }\end{array}$ & $\begin{array}{c}\text { Máximo de questões } \\
\text { em branco }\end{array}$ \\
\hline Domínio Físico/saúde & 17 & 14 & 3 \\
\hline Domínio Psicológico & 10 & 8 & 2 \\
\hline Domínio Pessoal & 16 & 13 & 3 \\
\hline Domínio Profissional & 35 & 28 & 7 \\
\hline \multicolumn{4}{|r}{ Fonte: Reis Junior (2008) }
\end{tabular}


Qualquer domínio que não apresentar o número mínimo de questões a serem respondidas deverá ter seu resultado retirado da pesquisa.

Para a análise dos resultados das aplicações do QWLQ-78, Reis Junior (2008) construiu uma escala de classificação da QVT. A escala em exame teve como base a proposta por Siviero (2003), em que todos os índices inferiores a 25 são considerados insatisfatórios, enquanto os índices situados entre 25 e 75 são considerados intermediários e os índices superiores a 75 são considerados satisfatórios. Esta escala foi adaptada para o instrumento QWLQ-78, perfazendo a seguinte configuração:

Quadro 8: Classificação proposta para o QWLQ-78

\begin{tabular}{|c|c|c|c|c|}
\hline \multicolumn{5}{|c|}{ QWLQ - 78 } \\
\hline Muito Insatisfatório & Insatisfatório & Neutro & Satisfatório & Muito Satisfatório \\
\hline 0 a 22,5 & 22,5 a 45 & 45 a 55 & 55 a 77,5 & 77,5 a 100 \\
\hline
\end{tabular}

Pode-se observar no quadro 8 que, nessa nova classificação, os índices satisfatórios de QVT tem inicio a partir de 55, podendo dizer que os colaboradores que atingem estes níveis em seus índices possuem uma QVT um tanto quanto satisfatória.

Para a tabulação dos dados e cálculo dos resultados do QWLQ-78, uma sintaxe exclusiva foi construída. Esta foi criada a partir de algoritmos em planilha eletrônica do programa Microsoft Excel for Windows. Esta sintaxe, além de apresentar os escores da avaliação da QVT, também apresenta a estatística descritiva da pesquisa: a média aritmética simples; o desvio padrão; o coeficiente de variação; o valor mínimo; o valor máximo; a amplitude. Esta apresenta, também, o índice de correlação de Pearson entre os domínios do QWLQ-78 e representa graficamente o resultado dos escores QVT abordados no referido instrumento (REIS JUNIOR, 2008).

\section{Metodologia}

Seguindo a metodologia utilizada para a seleção das questões que compõem o WHOQOLbref, a seleção das questões a compor a versão abreviada do QWLQ-78, o QWLQ-bref, foi realizada a partir da correlação das questões com o escore global da QVT, calculado a partir da média entre os quatro domínios do instrumento.

As correlações foram calculadas a partir dos dados coletados por Reis Junior (2008) da aplicação final do QWLQ-78, em que 378 colaboradores de quatro municípios do estado do Paraná - Curitiba, Ponta Grossa, Toledo e Pato Branco - compuseram a amostra.

Para a composição da versão abreviada do QWLQ-78, foram selecionadas as questões do primeiro quartil de cada domínio, mais correlacionadas com o escore global da QVT.

\section{Resultados e discussão}

Seguindo a metodologia proposta, e, atentando-se às questões cuja escala de respostas é invertida, as correlações das questões do domínio físico/saúde com o escore global da QVT podem ser visualizadas no quadro 9:

Quadro 9: Correlação das questões do domínio físico/saúde

\begin{tabular}{|c|c|}
\hline $\mathbf{N}^{\circ}$ da questão & Correlação \\
\hline 77 & 0,695 \\
\hline 69 & 0,489 \\
\hline 31 & 0,461 \\
\hline 36 & $-0,427$ \\
\hline 16 & $-0,423$ \\
\hline 61 & $-0,421$ \\
\hline 53 & $-0,400$ \\
\hline 26 & $-0,386$ \\
\hline
\end{tabular}




\begin{tabular}{|c|c|}
\hline 48 & $-0,319$ \\
\hline 65 & $-0,316$ \\
\hline 43 & $-0,300$ \\
\hline 6 & 0,292 \\
\hline 21 & 0,276 \\
\hline 57 & $-0,264$ \\
\hline 1 & 0,250 \\
\hline 73 & 0,191 \\
\hline 11 & $-0,025$ \\
\hline
\end{tabular}

As correlações das questões do domínio psicológico com o escore global da QVT podem ser visualizadas no quadro 10:

Quadro 10: Correlação das questões do domínio psicológico

\begin{tabular}{|c|c|}
\hline $\mathbf{N}^{\circ}$ da questão & Correlação \\
\hline 22 & 0,670 \\
\hline 32 & 0,630 \\
\hline 37 & 0,522 \\
\hline 44 & 0,497 \\
\hline 17 & $-0,476$ \\
\hline 12 & 0,471 \\
\hline 27 & 0,445 \\
\hline 2 & 0,375 \\
\hline 49 & $-0,336$ \\
\hline 7 & $-0,330$ \\
\hline
\end{tabular}

No quadro 11 são mostradas as correlações das questões do domínio pessoal com o escore global da QVT:

Quadro 11: Correlação das questões do domínio pessoal

\begin{tabular}{|c|c|}
\hline $\mathbf{N}^{\circ}$ da questão & Correlação \\
\hline 38 & 0,634 \\
\hline 66 & 0,616 \\
\hline 33 & 0,572 \\
\hline 45 & 0,572 \\
\hline 58 & 0,538 \\
\hline 28 & 0,533 \\
\hline 62 & 0,481 \\
\hline 70 & 0,433 \\
\hline 74 & 0,426 \\
\hline 23 & $-0,401$ \\
\hline 50 & $-0,387$ \\
\hline 18 & $-0,379$ \\
\hline 8 & 0,368 \\
\hline 54 & $-0,358$ \\
\hline 13 & 0,318 \\
\hline 3 & 0,310 \\
\hline
\end{tabular}

Por fim, o quadro 12 abarca as correlações das questões do domínio profissional com o escore global da QVT:

Quadro 12: Correlação das questões do domínio profissional

\begin{tabular}{|c|c|}
\hline $\mathbf{N}^{\circ}$ da questão & Correlação \\
\hline 78 & 0,728 \\
\hline 67 & 0,600 \\
\hline 59 & 0,587 \\
\hline 46 & 0,582 \\
\hline 35 & 0,568 \\
\hline
\end{tabular}




\begin{tabular}{|c|c|}
\hline 63 & 0,566 \\
\hline 72 & 0,557 \\
\hline 20 & 0,542 \\
\hline 24 & 0,533 \\
\hline 56 & 0,529 \\
\hline 76 & 0,525 \\
\hline 34 & $-0,519$ \\
\hline 52 & 0,503 \\
\hline 75 & 0,491 \\
\hline 39 & 0,487 \\
\hline 60 & 0,480 \\
\hline 30 & 0,466 \\
\hline 47 & 0,449 \\
\hline 5 & $-0,448$ \\
\hline 71 & 0,443 \\
\hline 41 & 0,437 \\
\hline 14 & 0,429 \\
\hline 68 & 0,428 \\
\hline 15 & 0,422 \\
\hline 51 & 0,413 \\
\hline 29 & 0,402 \\
\hline 19 & 0,397 \\
\hline 64 & 0,366 \\
\hline 55 & $-0,365$ \\
\hline 42 & 0,354 \\
\hline 10 & 0,290 \\
\hline 9 & 0,289 \\
\hline 25 & $-0,273$ \\
\hline 40 & 0,265 \\
\hline 4 & $-0,159$ \\
\hline
\end{tabular}

Das 78 questões que compõe o QWLQ-78, apenas 20 foram selecionadas para a versão abreviada do instrumento. Quatro questões do domínio físico/saúde, três do domínio psicológico, quatro do domínio pessoal e nove do domínio profissional. A ordenação das questões do QWLQbref seguiu a sequência de aparição destas no QWLQ-78, sendo apenas excluídas as questões não remanescentes para a versão abreviada e alterada a numeração sequencial, tendo início em 1 . O quadro 13 expõe as questões componentes do QWLQ-bref:

\begin{tabular}{|c|c|c|c|}
\hline DOMÍNIO & $\begin{array}{c}\text { QWLQ- } \\
78\end{array}$ & $\begin{array}{c}\text { QWLQ- } \\
\text { bref }\end{array}$ & QUESTÃO \\
\hline \multirow{4}{*}{$\begin{array}{l}\text { Domínio } \\
\text { físico }\end{array}$} & 31 & 4 & Em que medida você avalia o seu sono? \\
\hline & 36 & 8 & Em que medida algum problema com o sono prejudica seu trabalho? \\
\hline & 69 & 17 & Suas necessidades fisiológicas básicas são satisfeitas adequadamente? \\
\hline & 77 & 19 & Em que medida você se sente confortável no ambiente de trabalho? \\
\hline \multirow{3}{*}{$\begin{array}{c}\text { Domínio } \\
\text { psicológico }\end{array}$} & 22 & 2 & Em que medida você avalia sua motivação para trabalhar? \\
\hline & 32 & 5 & Como você avalia sua liberdade de expressão no seu trabalho? \\
\hline & 37 & 9 & Em que medida você avalia o orgulho pela sua profissão? \\
\hline \multirow{4}{*}{$\begin{array}{c}\text { Domínio } \\
\text { pessoal }\end{array}$} & 33 & 6 & Você se sente realizado com o trabalho que faz? \\
\hline & 38 & 10 & $\begin{array}{l}\text { Como você avalia a qualidade da sua relação com seus superiores e/ou } \\
\text { subordinados? }\end{array}$ \\
\hline & 45 & 11 & Em que medida sua família avalia o seu trabalho? \\
\hline & 66 & 15 & Em que medida você é respeitado pelos seus colegas e superiores? \\
\hline \multirow{5}{*}{$\begin{array}{c}\text { Domínio } \\
\text { profissional }\end{array}$} & 20 & 1 & Como você avalia a sua liberdade para criar coisas novas no trabalho? \\
\hline & 24 & 3 & Como você avalia a igualdade de tratamento entre os funcionários? \\
\hline & 35 & 7 & Em que medida você possui orgulho da organização na qual trabalha? \\
\hline & 46 & 12 & $\begin{array}{l}\text { Em que medida você está satisfeito com o seu nível de participação nas } \\
\text { decisões da empresa? }\end{array}$ \\
\hline & 59 & 13 & Você está satisfeito com o seu nível de responsabilidade no trabalho? \\
\hline
\end{tabular}




\begin{tabular}{|l|l|l|l|}
\hline \multirow{4}{*}{} & 63 & 14 & Você se sente satisfeito com os treinamentos dados pela organização? \\
\cline { 2 - 4 } & 67 & 16 & Você se sente satisfeito com a variedade das tarefas que realiza? \\
\cline { 2 - 4 } & 72 & 18 & Como você avalia o espírito de camaradagem no seu trabalho? \\
\cline { 2 - 4 } & 78 & 20 & O quanto você está satisfeito com a sua qualidade de vida no trabalho? \\
\hline
\end{tabular}

Para garantir que o instrumento abreviado possui a mesma validade que o instrumento original, foi realizado um comparativo entre os dois instrumentos. No gráfico 1 podem ser visualizados os resultados obtidos na aplicação final do QWLQ-78, realizada por Reis Junior (2008):

Gráfico 1: Resultados da versão completa do instrumento

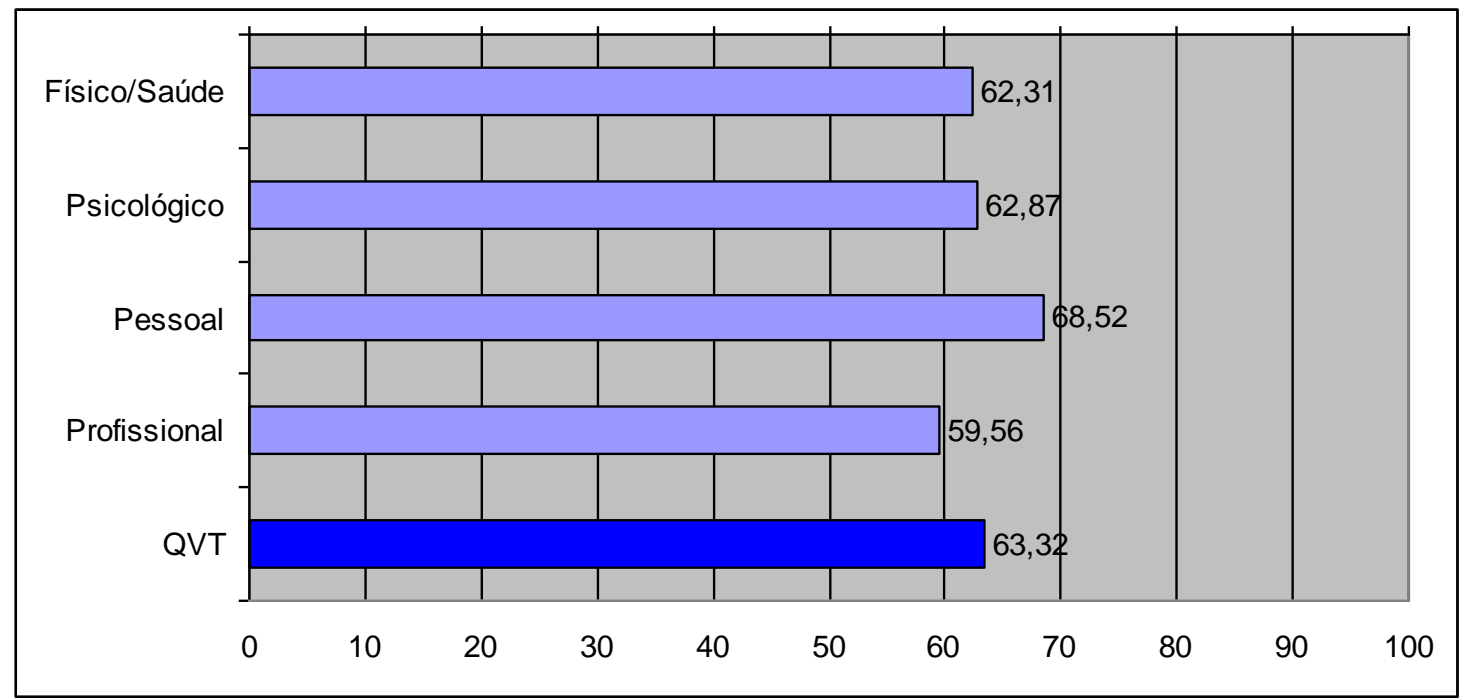

Por conseguinte, o gráfico 2 mostra os resultados dos domínios gerados através da média aritmética simples das respectivas questões selecionadas para compor o QWLQ-bref:

Gráfico 2: Resultados da versão abreviada do instrumento

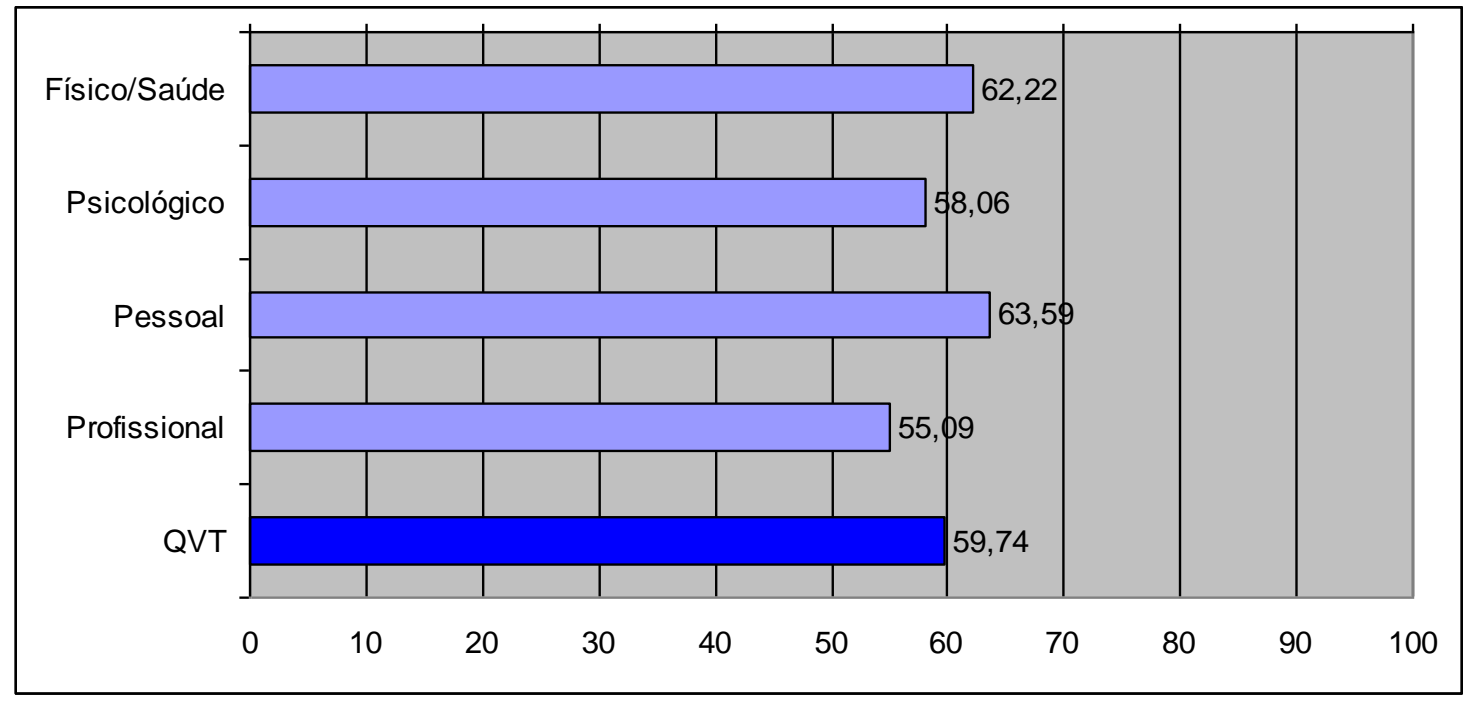

Como pode ser visualizado nos gráficos 1 e 2 , os resultados de ambos os instrumentos apresentam grande proximidade, não destoando em mais do que cinco pontos percentuais em nenhum domínio, tal qual o escore global da QVT, perfazendo com que o QWLQ-bref seja uma alternativa confiável para a avaliação QVT e que apresenta um tempo de aplicação e tabulação encurtado. 
Com relação à consistência interna, o QWLQ-bref apresentou um coeficiente alfa de Cronbach de valor 0,9035 , perfazendo com que tal propriedade psicométrica possa ser considerada como muito alta, superior, inclusive, ao QWLQ-78.

Tal qual o QWLQ-78, fora construída para o QWLQ-bref, uma ferramenta para o cálculo dos no software Microsoft Excel for Windows. Ao pesquisador compete apenas tabular os dados nos locais especificados, sendo que todos os cálculos são realizados de forma automatizada.

A versão final do QLWQ-bref e a ferramenta para o cálculo dos resultados do referido instrumento estão disponíveis no sítio eletrônico http://www.brunopedroso.com.br/qwlq-bref.html.

\section{Considerações finais}

Ainda que utilizados mundialmente e em grande escala, o elevado número de questões dos instrumentos WHOQOL-100 e WHOQOL-HIV passara a constituir um fator negativo na utilização de tais instrumentos. Em contrapartida a este imbróglio, a OMS empenhou-se nas respectivas versões abreviadas de tais instrumentos: o WHOQOL-bref e o WHOQOL-HIV-bref. Pautado na mesma justificação, almejou-se nesse trabalho a disponibilização de uma versão abreviada do QWLQ-78: o QWLQ-bref.

A metodologia utilizada para a seleção das questões foi embasada na adotada pela OMS para a criação das versões abreviadas dos instrumentos WHOQOL, sendo as questões a compor a versão abreviada selecionadas com base na correlação com o escore global da QVT, calculado a partir da média aritmética simples dos escores dos quatro domínios presentes no instrumento. Foram utilizados os dados coletados para a validação do QWLQ-78, em que o mesmo fora aplicado para 378 colaboradores de quatro municípios do estado do Paraná.

Fora remanescida para o QWLQ-bref um quarto do total de questões de cada domínio - 20 questões -, sendo estas as que apresentaram a maior correlação com o escore global da QVT do QWLQ-78. Em todos os domínios e no escore global da QVT, não houve variação superior a cinco pontos percentuais entre os resultados da versão original e a versão abreviada.

Em vista da dificuldade de utilização da sintaxe SPSS dos instrumentos WHOQOL, fora construída uma ferramenta para o cálculo dos resultados do QWLQ-bref a partir do software Microsoft Excel, uma plataforma maior acessibilidade e facilidade de utilização por parte da comunidade acadêmica brasileira.

Nessa perspectiva, conclui-se que, por meio do presente estudo, fora possível a disponibilização da versão abreviada do QWLQ-78 - o QWLQ-bref -, para avaliação da QVT, possibilitando a obtenção de resultados fidedignos ao instrumento original demandando menor tempo para aplicação e tabulação dos dados.

\section{Referências}

FLECK, M. P. A. Problemas conceituais em qualidade de vida. In: FLECK, M. P. A. et al. A avaliação de qualidade de vida: guia para profissionais da saúde. Porto Alegre: Artmed, 2008. p. $19-28$

FLECK, M. P. A. O instrumento de avaliação de qualidade de vida da Organização Mundial da Saúde (WHOQOL-100): características e perspectivas. Ciência e Saúde Coletiva, v. 5, p. 33-38, 2000.

PEDROSO, B.; PILATTI, L. A.; REIS, D. R. Cálculo dos escores e estatística descritiva do WHOQOL-100 utilizando o Microsoft Excel. Revista Brasileira de Qualidade de Vida, Ponta Grossa, v. 01, n. 01, p. 23-32, jan./jun. 2009.

PILATTI, L. A. Qualidade de Vida e Trabalho: perspectivas na sociedade do conhecimento. Estratégias e Políticas em Qualidade de Vida. Campinas: IPES Editorial, 2005. p. 41-50. 
PILATTI, L. A.; BEJARANO, V. C. Qualidade de vida no trabalho: leituras e possibilidades no entorno. Gestão da qualidade de vida na empresa. Campinas: IPES Editorial, 2005. p. 85-104.

REIS JÚNIOR, D. R. Qualidade de vida no trabalho: construção e validação do questionário QWLQ-78. 2008. 114 f. Dissertação (Mestrado em Engenharia de Produção) - Programa de PósGraduação em Engenharia de Produção, Universidade Tecnológica Federal do Paraná, Ponta Grossa. 